\title{
The brittle-to-ductile transition in tensile and impact behavior of hybrid carbon fibre/self-reinforced polypropylene composites
}

\author{
Marina Selezneva $^{\mathrm{a}, *}$, Yentl Swolfs ${ }^{\mathrm{a}}$, Amalia Katalagarianakis ${ }^{\mathrm{a}}$, Tomoko Ichikawa ${ }^{\mathrm{b}}$, \\ Noriyuki Hirano $^{\mathrm{b}}$, Ichiro Taketa ${ }^{\mathrm{c}}$, Takuya Karaki ${ }^{\mathrm{b}}$, Ignaas Verpoest ${ }^{\mathrm{a}}$, Larissa Gorbatikh ${ }^{\mathrm{a}}$ \\ ${ }^{a}$ Department of Materials Engineering, KU Leuven, Kasteelpark Arenberg 44, 3001 Leuven, Belgium \\ ${ }^{\mathrm{b}}$ Composite Materials Research Laboratories, Toray Industries, Inc., 1515 Tsutsui Masaki-cho Iyogun, 791-3193 Ehime, Japan \\ ${ }^{c}$ Technical Center, Toray Carbon Fibers Europe S.A. (CFE), Route Départementale 817, 64170 Lacq, France
}

\section{A R T I C L E I N F O}

\section{Keywords:}

A. Hybrid

A. Polymer (textile) fibres

A. Discontinuous reinforcement

B. Mechanical properties

\begin{abstract}
A B S T R A C T
Hybrid composites combining two fibre types with distinctly different mechanical properties have the potential to surpass the stiffness-toughness dilemma, which is characteristic to standard (single fibre type) composite materials. The current work demonstrates this potential on the example of carbon fibre/self-reinforced polypropylene (SRPP) hybrids. The aim is to understand the transition from brittle to ductile behaviour under tensile and impact loadings and to identify the parameters affecting this transition. It was found that the volume fraction $\left(\mathrm{V}_{\mathrm{f}}\right)$ of carbon fibres at which the transition occurs can be increased by using a dispersed layup with thinner layers. The use of a high adhesion matrix results in higher modulus and yield strength but lowers the transition $\mathrm{V}_{\mathrm{f}}$. The experimental program is supported by analytical models used to predict modulus, strength and energy absorption. Results indicate that pseudo-ductile carbon fibre/SRPP hybrids are competitive with composites produced from bulk and sheet moulding compounds.
\end{abstract}

\section{Introduction}

Most materials conform to the stiffness-toughness dilemma, meaning that they are either stiff but brittle or tough but compliant. Conventional composite materials are no exception in this regard. On one side of the spectrum are carbon fibre composites. They offer high stiffness and strength that make them attractive for a wide range of applications from sporting goods to aircraft components. However, they fracture in a brittle manner with little or no warning before final failure, hence leading to conservative designs and over-designed components. On the other side of the spectrum are self-reinforced polymer composites, in which the matrix and the reinforcement are made from the same polymeric material. These composites exhibit high levels of ductility and toughness [1-4]. However, they have low stiffness and yield stress, which has been hindering their implementation in structural and semi-structural applications.

This stiffness-toughness dilemma has stimulated research in the field of pseudo-ductile hybrid composites. The latter combine both stiff but brittle (low elongation) and tough (high elongation) fibres or reinforcements [5-14]. For instance, Czél et al. [5,7] developed pseudoductile hybrids by combining carbon fibres with a failure strain of $2 \%$ with glass fibres with a failure strain of $5 \%$. They achieved gradual damage development resulting in a pseudo-ductile response with failure strains up to $4 \%$.

Much higher failure strains ( $>15 \%$ ) were achieved by Swolfs et al. [8-10] by hybridising continuous carbon fibres with self-reinforced polypropylene (SRPP), which has a failure strain of up to $20 \%$. In that set of studies, various architectures (unidirectional vs. woven) and dispersion levels (layer-by-layer vs. co-woven) were tested. While high ductility was achieved with these hybrids, the stress-strain curves were not smooth. They showed repeated load-drops caused by fragmentation of the carbon fibre component accompanied by delamination between carbon fibre layers and SRPP, or debonding between carbon fibre and SRPP tapes in the co-woven configuration. It has been difficult to suppress delamination and eliminate the load drops in these hybrids because of the high levels of energy released when carbon fibres fracture. For a more comprehensive review of hybrid composites, the reader is referred to [15].

Design of ductile hybrids is challenging and requires a thorough understanding of the failure mechanisms that occur during loading [15-17]. The damage scenarios that can occur in interlayer hybrids were outlined by Czél et al. [7,16] and Swolfs et al. [9]. After the initial failure of the low elongation layer hybrid composites may undergo one of the following events $[7,9,16-18]$ :

\footnotetext{
* Corresponding author.

E-mail address: marina.selezneva@kuleuven.be (M. Selezneva).
} 
(a) instant failure of the high elongation layer as it cannot sustain the load that is transferred to it,

(b) catastrophic delamination, which is then followed by the failure of the high elongation layers,

(c) stable fragmentation of the low elongation material, which is accompanied by no or minimal delamination, and finally failure of the high elongation material upon further load increase.

Initiation and propagation of damage depend primarily on the strength, stiffness, volume fractions of the high and low elongation components, the stacking sequence, ply thickness and mode II fracture toughness of the interface between the high and low elongation layers $[7,9,16-18]$. Depending on the combination of these properties, failure can be either gradual or abrupt (showing no loss of stiffness up to the final failure). Hence, the right combination of parameters is required to achieve a pseudo-ductile response.

Impact properties of hybrids have been the focus of numerous studies [15]. It was shown that the stacking sequence has a strong influence on the impact performance of composites, as it affects the flexural stiffness and strength as well as the damage mechanisms. Studies on hybrids have shown that penetration impact resistance is improved when the low elongation layers are placed inside the hybrid and are shielded by the high elongation layers at the outside [19-21].

The present work investigates the tensile and impact properties of a novel type of hybrid composites that contain randomly oriented discontinuous carbon fibres and woven SRPP. The brittle-to-ductile transition is of key interest here. It is desirable to increase the volume fraction $\left(\mathrm{V}_{\mathrm{f}}\right)$ at which this transition occurs to increase the stiffness and yield stress while maintaining the pseudo-ductile behaviour and impact performance. The effect of the stacking sequence and the fibre-matrix interface on the $\mathrm{V}_{\mathrm{f}}$ at the transition will be investigated. To achieve a stronger interface between the fibres and the matrix, maleic anhydride grafted polypropylene (MAPP) is used to impregnate the carbon fibres instead of the regular polypropylene (PP). Simple analytical models are proposed for prediction of stiffness, strength and the transition from brittle to ductile tensile behaviour.

\section{Experimental}

\subsection{Materials and composite processing}

Hybrid layups consisted of carbon fibre mats, PP tape fabrics and PP films, and each of these materials will be discussed hereafter. The dry carbon fibre mats were provided by Toray Industries Inc. (Japan) and consisted of in-plane randomly oriented $6 \mathrm{~mm}$ long T700S fibres held together by a binder, see Fig. 1a. The areal density of the mats was either 10 or $30 \mathrm{~g} / \mathrm{m}^{2}$. A balanced $2 / 2$ twill PP tape fabric was provided by Propex Fabrics GmbH (Germany), see Fig. 1b. The tapes used to create the fabric are drawn 10-15 times, have a rectangular cross-section and are about $2.4 \mathrm{~mm}$ wide. During the weaving process, some of the tapes in both the warp and the weft directions are folded along their
Table 1

Summary of tested composites. $S$ stands for SRPP, / for PP or MAPP films, and 10 or 30 represent the areal weight in $\mathrm{g} / \mathrm{m}^{2}$ of the carbon fibre mat. Hybrid configurations that were considered for each film type are identified by $X$.

\begin{tabular}{|c|c|c|c|c|}
\hline Layup & $\begin{array}{l}\text { Internal } \\
\text { fibre volume } \\
\text { fraction }(\%)\end{array}$ & $\begin{array}{l}\text { Global } \\
\text { fibre volume } \\
\text { fraction } V_{f}(\%)\end{array}$ & $\begin{array}{l}\text { Film type } \\
\text { PP }\end{array}$ & MAPP \\
\hline $\begin{array}{l}\mathrm{S} / \mathrm{S} / \mathrm{S} / \mathrm{S} / \mathrm{S} / \mathrm{S} / \mathrm{S} / \mathrm{S} / \mathrm{S} / \mathrm{S} / \\
\mathrm{S} / \mathrm{S}\end{array}$ & 0 & 0 & $\mathrm{X}$ & \\
\hline $\mathrm{S} / \mathrm{S} / / 30 / / / / 30 / / \mathrm{S} / \mathrm{S}$ & 16.7 & 4.1 & $\mathrm{X}$ & \\
\hline $\mathrm{S} / / 30 / / \mathrm{S}$ & 16.7 & 4.4 & $\mathrm{X}$ & $\mathrm{X}$ \\
\hline $\begin{array}{l}{[\mathrm{S} / / 30 / / \mathrm{S} / / 30 / / \mathrm{S} / /} \\
\quad 15] \mathrm{s}\end{array}$ & 16.7 & 6.2 & & $\mathrm{X}$ \\
\hline$/ / 30 / / \mathrm{SS} / / 30 / /$ & 16.7 & 6.9 & & $\mathrm{X}$ \\
\hline $\mathrm{S} / / 30 / / / / 30 / / \mathrm{S}$ & 16.7 & 6.9 & $\mathrm{X}$ & $\mathrm{X}$ \\
\hline $\mathrm{S} / / 30 / / / / 30 / / / / 30 / / \mathrm{S}$ & 16.7 & 8.6 & $\mathrm{X}$ & $\mathrm{X}$ \\
\hline$/ / 30 / / S / / 30 / / S / / 30 / /$ & 16.7 & 8.6 & $\mathrm{X}$ & $\mathrm{X}$ \\
\hline $\begin{array}{l}{[\mathrm{S} / / 30 / / / / 30 / / \mathrm{S} / /} \\
30 / / / / 30 / / \mathrm{S} / / \\
30 / /] \mathrm{s}\end{array}$ & 16.7 & 9.0 & $\mathrm{X}$ & \\
\hline $\begin{array}{r}S / / 30 / / / / 30 / / / / \\
30 / / / / 30 / / S\end{array}$ & 16.7 & 9.8 & $\mathrm{X}$ & $\mathrm{X}$ \\
\hline $\begin{array}{c}{[\mathrm{S} / / 30 / / / / 30 / / / /} \\
30 / / / / 30 / /] \mathrm{s}\end{array}$ & 16.7 & 12.3 & & $\mathrm{X}$ \\
\hline $\begin{array}{l}/ / 30 / / / / 30 / / / / 30 / / / / / \\
30 / /\end{array}$ & 16.7 & 16.7 & $\mathrm{X}$ & $\mathrm{X}$ \\
\hline$/ S / / 10 / S / S / S / 10 / / S /$ & 8.5 & 1.2 & $\mathrm{X}$ & \\
\hline$S / 10 / S$ & 11.8 & 1.7 & $\mathrm{X}$ & $\mathrm{X}$ \\
\hline $\begin{array}{c}/ \mathrm{S} / / / 30 / / \mathrm{S} / \mathrm{S} / \mathrm{S} / / \\
30 / / / \mathrm{S} /\end{array}$ & 14.3 & 3.2 & $\mathrm{X}$ & \\
\hline$/ \mathrm{S} / / 30 / \mathrm{S} / \mathrm{S} / \mathrm{S} / 30 / / \mathrm{S} /$ & 21.7 & 3.5 & $\mathrm{X}$ & \\
\hline$/ \mathrm{S} / / 30 / \mathrm{S} / \mathrm{S} / 30 / / \mathrm{S} /$ & 21.7 & 4.2 & $\mathrm{X}$ & \\
\hline$/ \mathrm{S} / / 30 / \mathrm{S} / 30 / / \mathrm{S} /$ & 21.7 & 5.3 & $\mathrm{X}$ & \\
\hline $\begin{array}{c}\mathrm{S} / / / / / / 303030 \\
10 / / / / / / \mathrm{S}\end{array}$ & 18.8 & 9.5 & $\mathrm{X}$ & \\
\hline
\end{tabular}

length, which makes them look narrower in Fig. 1b. This manufacturing feature is known as overfeeding and is described in more detail in [1]. The average area density of the produced fabric is $130 \mathrm{~g} / \mathrm{m}^{2}[1,2]$. Upon heating, the outer sheath of the PP tapes melts, while the inner core maintains its molecular orientation. During the cool-down, the molten PP consolidates and forms the "matrix" component of the SRPP layer [22]. The purpose of the PP films is therefore not to impregnate the PP tape fabric, but to impregnate the carbon fibre mat.

Propex Fabrics $\mathrm{GmbH}$ also provided two types of $20 \mu \mathrm{m}$ thick films: homopolymer PP and maleic-anhydride modified PP, in short MAPP. The homopolymer PP is the same grade as that used to produce the PP tape fabric. This PP has low affinity to carbon fibres, resulting in poor adhesion between the fibres and PP [23]. MAPP on the other hand has better adhesion to carbon fibres. It was previously shown that interfacial shear strength between carbon fibres and polypropylene matrix can be increased from 6 to $16 \mathrm{MPa}$ by switching from PP to MAPP [23]. The actual content of the modifier was not disclosed.

Different interlayer hybrids were produced, as summarised in Table 1. "S" stands for SRPP, "/" for a single PP or MAPP film, and the

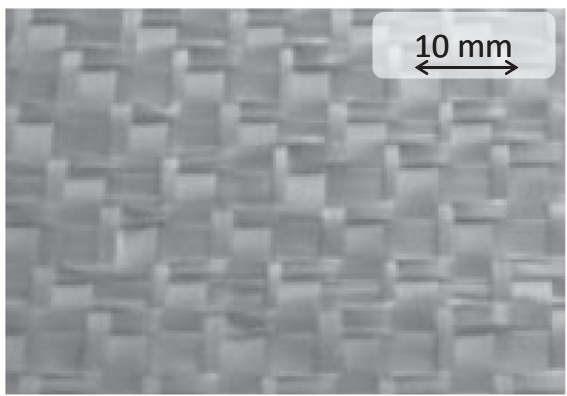

(b)

Fig. 1. Structure of the materials studied: (a) carbon fibre mat and (b) twill PP tape fabric. 
values " 10 " and " 30 " represent the areal weight in $\mathrm{g} / \mathrm{m}^{2}$ of the carbon fibre mat. Two types of layups were considered: the nominal and the dispersed. In the nominal layup, the carbon fibre mats were stacked in the centre to form a single thick layer (e.g. $S / / 30 / / / / 30 / / / / 30 / / S$ ); whereas, in the dispersed layup, the individual carbon layers were separated from each other by SRPP plies $(/ / 30 / / \mathrm{S} / / 30 / / \mathrm{S} / / 30 / /)$. Two fibre volume fractions values were defined and pre-calculated, see Table 1. The "internal fibre volume fraction" corresponds to the fibre content inside of the carbon fibre layer and not the hybrid as the whole. It is calculated by accounting for the areal weight and density [24] of the carbon fibres and the total thickness of the PP films. In this calculation, it was assumed that the PP films entirely impregnate the carbon mat and do not flow into the SRPP layer, and that the reverse is true for the matrix created by melting PP tapes. The "global fibre volume fraction" $\left(V_{f}\right)$ represents the overall carbon fibre content in the hybrid, and hence the thickness of the SRPP plies is also considered. For example, in the $\mathrm{S} / / 30 / / \mathrm{S}$ hybrid the carbon fibre volume fraction inside of the carbon layer is $16.7 \%$ (for $/ / 30 / /$ ) and the global $V_{f}$ is $4.4 \%$. Nonhybrid panels of only SRPP or carbon fibre/PP layers were also produced for comparison, see Table 1.

All the panels were manufactured by hot compaction at $188^{\circ} \mathrm{C}$ with a hold time of $5 \mathrm{~min}$ at $39 \mathrm{bar}$, and an average cooling rate of $35^{\circ} \mathrm{C} / \mathrm{min}$. Two $1 \mathrm{~mm}$ thick aluminium plates were used as a mould. Additional information on the manufacturing process and the optimisation of the processing conditions can be found in [22].

\subsection{Tensile tests}

To measure the tensile properties, the ASTM D3039 standard was followed. Specimens were $250 \mathrm{~mm}$ long and $25 \mathrm{~mm}$ wide, and had a gauge length of $150 \mathrm{~mm}$. Specimens were not tabbed, but instead a piece of emery cloth was placed between the specimen and the grips to prevent slippage. SRPP and hybrid specimens were loaded at a displacement rate of $7.5 \mathrm{~mm} / \mathrm{min}(5 \% / \mathrm{min})$, and carbon fibre/PP specimens at $2 \mathrm{~mm} / \mathrm{min}(1.3 \% / \mathrm{min})$. The speed was adjusted to better fit the recommendations for the test duration that are given in the ASTM standard.

Initial strains $(<1.5 \%)$ were measured using the 2D digital image correlation (DIC) technique by monitoring the deformation of the speckle pattern on the specimen surface over the entire area. The quality of the speckle pattern deteriorated at higher strains, because the carbon fibre and SRPP layers became damaged. Thus, surface strains could not be measured accurately anymore. In the strain range where DIC gave erroneous data, strain values were calculated using the crosshead displacement [9]. The stress-strain curve generated using the displacement data was shifted so that in the initial strain range it would overlap with the curve plotted using the DIC data [9]. This adjustment ensured the continuity of the reconstructed stress-strain curve. The accuracy of this method was previously validated in [9]. Modulus was calculated using data in the $0.1-0.3 \%$ strain range, and the yield point was determined by using a $0.2 \%$ strain offset.

\subsection{Impact tests}

Instrumented penetration impact tests were conducted to evaluate the energy absorption properties. Impact samples had a size of $100 \times 100 \mathrm{~mm}$, and were clamped by a circular clamp with inner and outer diameters of 40 and $60 \mathrm{~mm}$, respectively. A force of $2800 \mathrm{~N}$ was exerted on the clamp, which corresponds to a clamping pressure of $1780 \mathrm{kPa}$. A hemispherical striker with a diameter of $20 \mathrm{~mm}$ was dropped from a height of $1 \mathrm{~m}$. For carbon/PP specimens, a striker with a weight of $3.17 \mathrm{~kg}$ was used, while for all other specimens (SRPP and hybrids) the striker was $26.17 \mathrm{~kg}$. A lower weight had to be used for carbon/PP specimens, because they absorbed significantly less energy and data recording could not be triggered properly if the heavy weight was used. Since the height remained the same, the impact velocity also remained the same.

The impact performance of hybrids was quantified by computing the total absorbed energy and the shape parameter (SP). The total absorbed energy is calculated by finding the area under the entire force-displacement curve recorded during the test, where the displacement data represents the displacement of the impactor. Two types of normalisation were performed. In the first assessment, the total absorbed energy was normalised with respect to the panel thickness, and in the further analysis with respect to the number of SRPP plies. Both sets of data are reported and discussed in Section 4.3. The shape parameter is defined as the ratio between the energy absorbed after and before the peak load. Alternatively, this ratio has also been referred to as the ductility index in other publications $[25,26]$ that used the Charpy pendulum method to determine the impact performance. We found this terminology misleading with respect to the properties of SRPP measured by a falling weight penetration impact test. SRPP is a ductile and high energy absorbing material but has a low ductility index [22]. The Charpy and penetration impact tests are two different tests, and it is difficult to compare their results directly. Hence, it was decided to use the term shape parameter instead. This definition was used to compare the shapes of the force-displacement curves of hybrids with those of SRPP and carbon/PP samples. The classification of a hybrid as brittle or ductile was based on the shape parameter and phenomenological grounds (i.e. localised vs. dispersed damage) as discussed further in the results section.

\section{Results: tensile behaviour}

Various hybrid configurations were tested, as shown in Table 1. To simplify the analysis, the initial part of the discussion will focus on the specimens with an internal fibre volume fraction of $16.7 \%(/ / 30 / /)$ (see Table 1), produced using PP (not MAPP) and having the nominal layup (implying SRPP on the outside and a carbon layer on the inside). The next sections cover the effect of matrix adhesion and layup. Finally, analytical expressions that can be used to estimate the modulus and the ultimate tensile strength (UTS) and the $\mathrm{V}_{\mathrm{f}}$ at which the transition from brittle to ductile behaviour occurs are proposed.

In this study, the specimen was considered to be ductile if it reached its UTS at strains higher than $2 \%$. On the other hand, if the UTS corresponded to the stress level at which the carbon layer fractured (at $\approx 2 \%$ strain), the specimen was classified at brittle. This definition was adopted to make a clear distinction between the two types of damage scenarios observed in the carbon fibre mat/SRPP hybrids. The brittle and ductile hybrid composites differ in their failure mechanisms. The ductile hybrids undergo dispersed damage development that encompasses ply fragmentation, fibre/matrix debonding and matrix cracking. Fragmentation refers to the formation of multiple throughthe-thickness cracks in the carbon layer that span the whole width of the specimen. The brittle hybrids exhibit a single localised crack of the carbon layer. The proposed definition differentiates between truly or ideally brittle and ductile behaviours. This definition is conservative and is applicable from the engineering point of view when the design requirements are stringent. Yet, the highly ductile nature of SRPP and the complex failure phenomena that occur in these hybrids, gives rise to what can be considered as a transitional behaviour. Following the initial load drop at $2 \%$ strain, such hybrids can sustain a fairly high load level up to the final failure.

\subsection{Effect of the carbon fibre volume fraction}

Fig. 2 presents the stress-strain curves of carbon/SRPP hybrids, SRPP and carbon/PP specimens. Pseudo-ductility with failure strains above $10 \%$ is achievable when the global $V_{f}$ of carbon fibres is lower than $7 \%$, which is almost half of the $\mathrm{V}_{\mathrm{f}}$ of non-hybridised carbon fibre/ PP specimen (16.7\%). Such hybrids have superior ductility in comparison to carbon/PP composites that fail at $2 \%$ strain and also offer a 


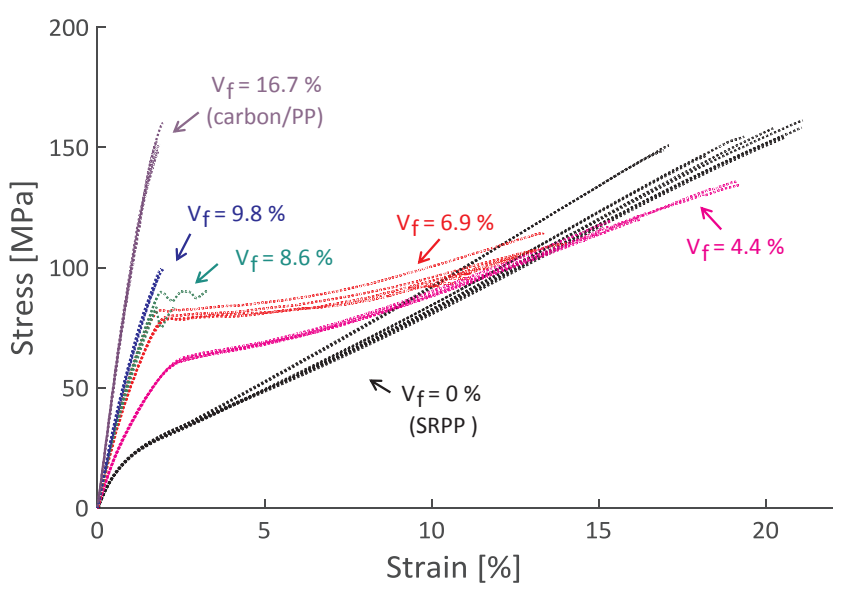

Fig. 2. Tensile stress-strain curves of carbon/PP and SRPP composites and their hybrids. (For interpretation of the references to colour in this figure legend, the reader is referred to the web version of this article.)

twofold increase of modulus over that of SRPP (6.1 vs. $3.1 \mathrm{GPa})$. In contrast, unidirectional carbon/glass hybrids that were developed at the University of Bristol achieve a failure strain up to $4 \%$, but at a significantly higher stiffness [5-7]. Carbon/SRPP hybrids are significantly more ductile than their carbon/glass counterparts, due to a much higher failure strain of SRPP in comparison with glass (20 vs. $5 \%$ ), but with a lower stiffness. The apparent increase in the yield point is also clearly visible, and will be discussed in more details in the next section.

\subsection{Effect of matrix adhesion}

Non-hybrid carbon fibre composites produced with high-adhesion MAPP matrix were stronger and exhibited a linear stress-strain response over a longer stress/strain interval in comparison to composites with low-adhesion PP, as shown in Fig. 3a. As opposed to the carbon/ MAPP specimens, carbon/PP ones showed extensive fibre debonding and pull-out, which are expected when interface adhesion is poor, as shown in Fig. $3 \mathrm{~b}$.

Hybrids containing MAPP have a higher knee-point and a lower transition $V_{f}$ than those containing regular PP, as shown in Fig. 4. Based on the definition of the truly brittle and ductile behaviours that was proposed, PP-based specimens with $\mathrm{V}_{\mathrm{f}}$ of $6.9 \%$ would be ductile, whereas MAPP-based ones are brittle. Indeed, the hybrid with MAPP matrix reached its UTS at $2 \%$ strain. Fracture of the carbon layer resulted in a load drop followed by a pseudo-plateau that corresponds to the gradual debonding of SRPP. This stable debonding allowed the hybrid to retain some $(70 \%)$ of its load carrying capacity up to the strain of $8 \%$. Due to the relatively high load retention and high final failure strain reached by this hybrid, its behaviour can be deemed as transitional. This type of response can also be considered as ductile based on alternative definitions in the literature [8-10]. In this paper, this behaviour is treated as transitional to differentiate it from the ductile response shown in Fig. 4a, since these hybrids have different damage mechanism and from the brittle response because of the high load retention and failure strain. Overall, the choice of the definition depends on the potential application and the main design parameters, which may be strength, strain at UTS or overall toughness.

Matrix adhesion also has a strong influence on the yield stress, as depicted in Fig. 5. Modulus, yield stress and the knee-point are directly related to the stress-strain response of the carbon fibre layer, as will be shown in Section 3.4 when describing the proposed analytical models.

\subsection{Effect of layup}

The brittle-to-ductile transition was found to occur between $6.9 \%$ and $8.6 \%$ of the global $V_{f}$ for PP-based hybrids and between $4.4 \%$ and $6.9 \%$ for MAPP-based hybrids. This transition $V_{f}$ can be increased by switching from the nominal layup with a single (typically thick) carbon fibre layer in the centre to a dispersed layup with the carbon fibre layers separated by the SRPP plies. For instance, Fig. 6 shows a comparison between two hybrids with the same $\mathrm{V}_{\mathrm{f}}$ and film type, but different layups. The hybrid with the nominal layup is brittle, while the dispersed one is ductile. Post-mortem examination of the ductile hybrids with a dispersed layup (PP matrix and $V_{f}=9 \%$ ) showed that there are clear sites of fragmentation in the material. However, these cracks did not propagate through the entire thickness of the specimen and were impeded by the SRPP layers, as shown in Fig. 7. Hence, the dispersed configuration helps to achieve a gradual and stable damage development in the carbon fibre layer.

\subsection{Estimation of the initial response}

Elastic properties of hybrids can typically be estimated using the rule-of-mixtures [15]. To account for the non-linear behaviour of SRPP, the stress-strain curve of hybrids can be calculated by applying the
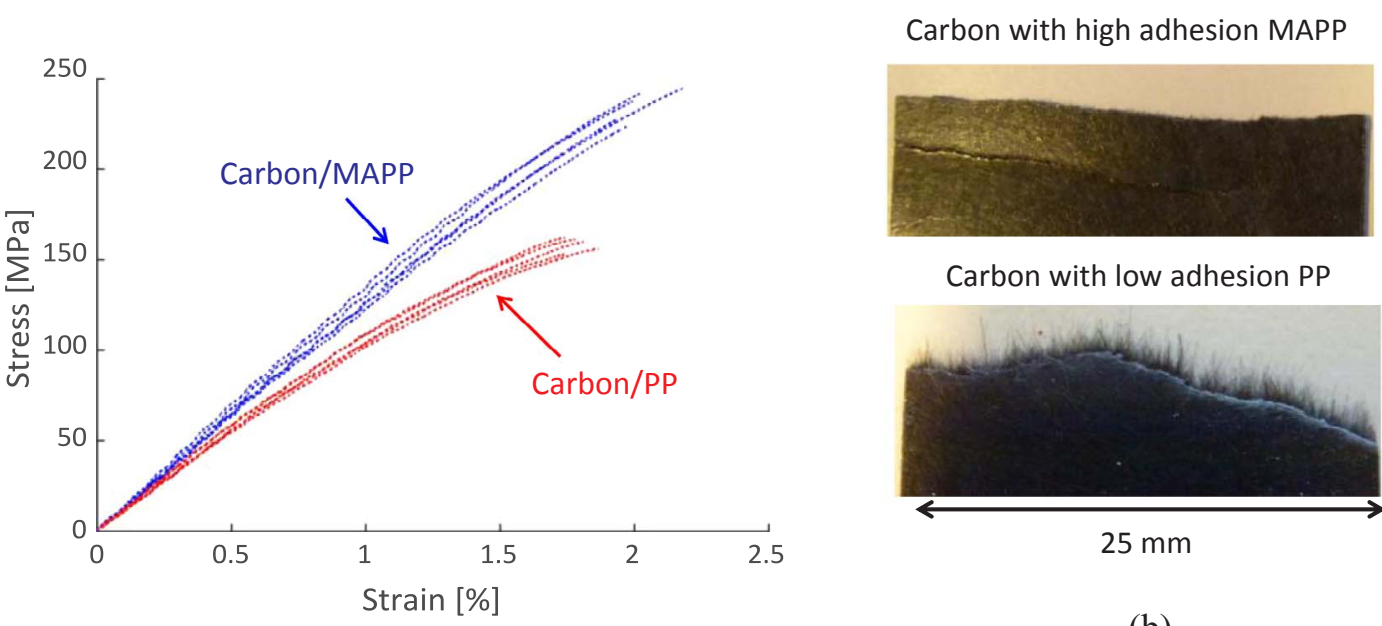

Carbon with low adhesion PP

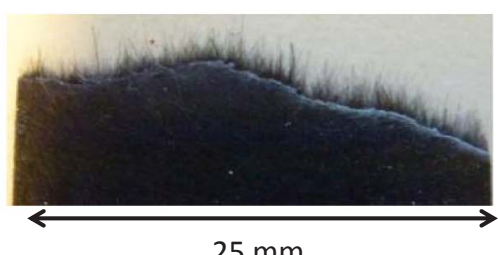

(b)

(a)

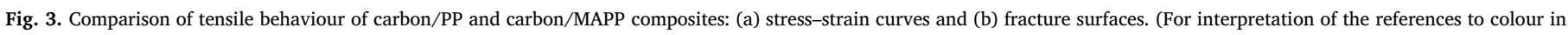
this figure legend, the reader is referred to the web version of this article.) 


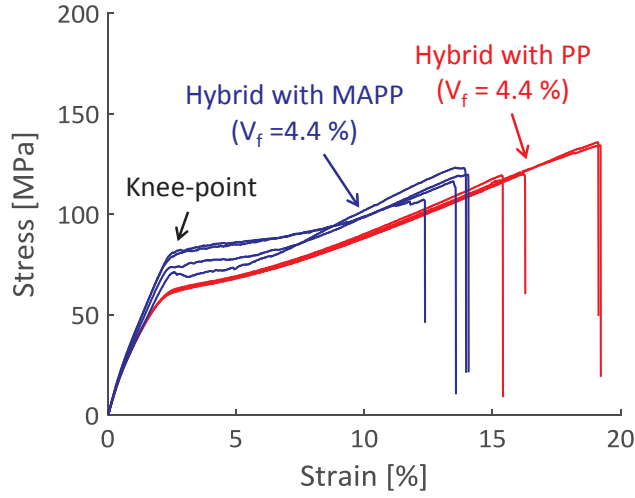

(a)

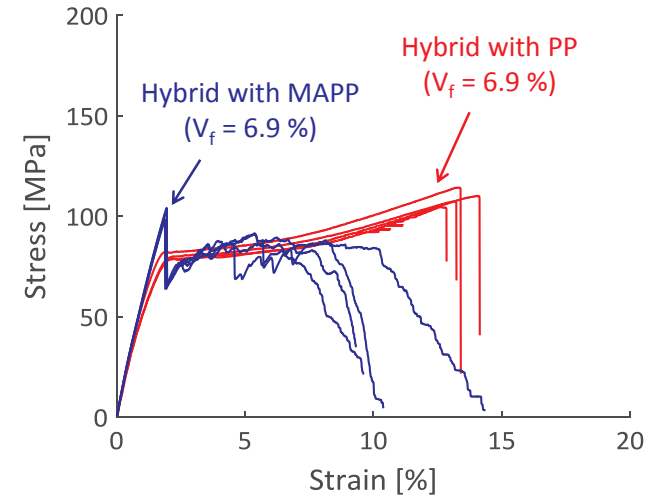

(b)

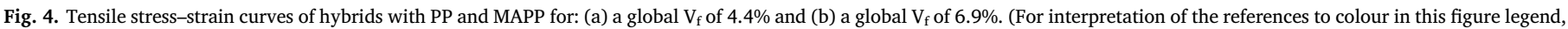
the reader is referred to the web version of this article.)

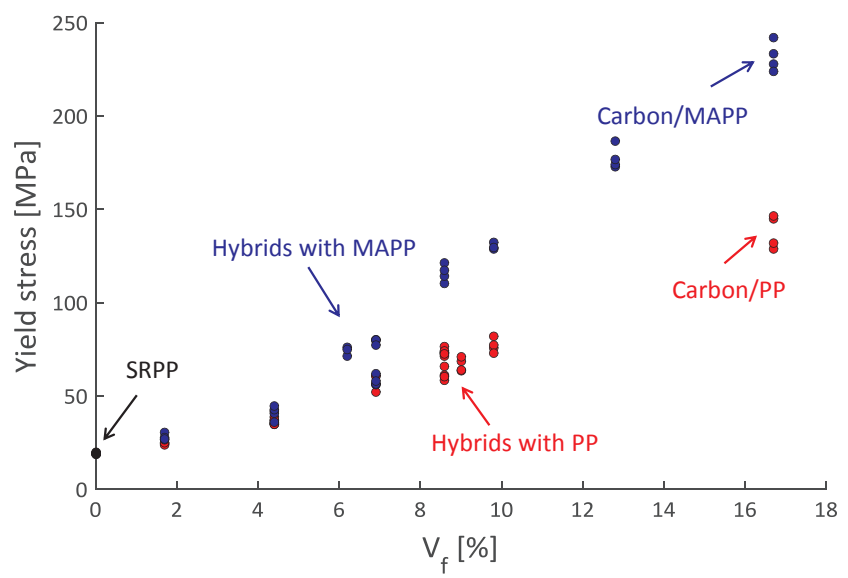

Fig. 5. Effect of the matrix adhesion (PP vs. MAPP) and $V_{f}$ on the yield stress. (For interpretation of the references to colour in this figure legend, the reader is referred to the web version of this article.)

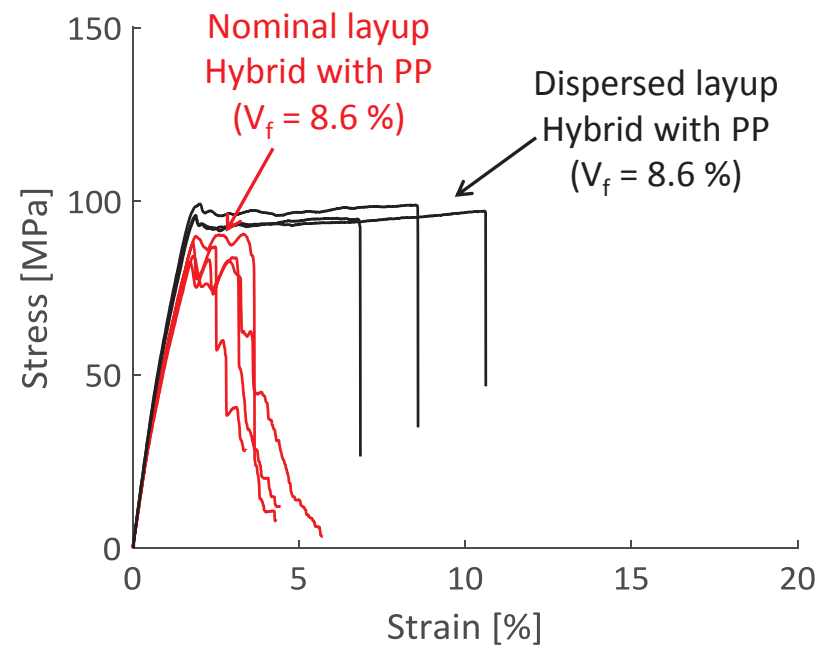

Fig. 6. Tensile stress-strain curves of hybrids with $\mathrm{PP}, \mathrm{V}_{\mathrm{f}}$ of $8.6 \%$ and two type of layups: nominal vs. dispersed. (For interpretation of the references to colour in this figure legend, the reader is referred to the web version of this article.)

rule-of-mixtures at incremental values of $\operatorname{strain}\left(\varepsilon_{\mathrm{i}}\right)$, as shown in Eq. (1).

$\sigma_{i}\left(\varepsilon_{i}\right)=\frac{\left(\sigma_{S R P P}\right)_{i} t_{S R P P}+\left(\sigma_{C}\right)_{i} t_{C}}{t_{S R P P}+t_{C}}$,

where $\sigma_{\mathrm{SRPP}}$ and $\sigma_{\mathrm{C}}$ are the stresses in the SRPP and the carbon plies at strain $\varepsilon_{\mathrm{i}}, \sigma_{\mathrm{i}}$ is the global stress in the hybrid at strain $\varepsilon_{\mathrm{i}}$, and $t_{\mathrm{SRPP}}$ and $t_{\mathrm{C}}$ are the thickness of the SRPP and the carbon plies, respectively.

Comparison between the experimental and the modelling results for the part before failure of the carbon layer is presented in Fig. 8a. Overall, a good correlation between the calculated and the measured stress-strain curves is observed. Moreover, these curves can be used to estimate the Young's modulus by considering the stress-strain data in the $0.1-0.3 \%$ strain range, as shown in

Fig. 8b. Similarly, the generated stress-strain curves can be used to estimate yield stress. Hence, the initial response of these hybrids can be predicted by the incremental rule-of-mixtures.

\subsection{Estimation of the strength}

Two criteria were proposed in [5] for achieving pseudo-ductile behaviour of hybrids: strength-based and fracture toughness-based. These criteria describe the possible scenarios that can take place after the fracture of the brittle layer. The strength-based criterion evaluates the ability of the ductile layer (e.g. SRPP) to sustain the load that is transferred to it and is based on the concept of stress redistribution to the still unbroken layers. The fracture toughness criterion assesses the likelihood of delamination propagation between the layers starting from the fracture of the brittle layer. While accurate consideration of both criteria is required to model the entire stress-strain curve of the hybrid, the application of the strength-based criterion alone is needed to predict the ultimate tensile strength (UTS). This criterion is analogous to the ply-by-ply method used to predict the strength of laminates [27].

The expressions used to define the strength-based criterion are derived by relating the global stress in the hybrid $(\sigma)$ to the stresses carried by the individual layers. This is achieved by summing the loads (per unit width) for each component, while assuming that the layers are perfectly bonded and experience the same strain, as shown in Eq. (2):

$\sigma\left(t_{S R P P}+t_{C}\right)=\sigma_{S R P P} t_{S R P P}+\sigma_{C} t_{C}$.

In this equation, $\sigma_{\mathrm{C}}$ is the stress in the carbon fibre ply, $\sigma_{\mathrm{SRPP}}$ is the stress in SRPP, and $t_{\mathrm{SRPP}}$ and $t_{\mathrm{C}}$ are the layer thicknesses. This equation is then rearranged to solve for $\sigma$, as shown in Eq. (3):

$\sigma=\frac{\sigma_{S R P P} t_{S R P P}+\sigma_{C} t_{C}}{t_{S R P P}+t_{C}}$.

To calculate the stress in the hybrid $\left(\sigma_{1}\right)$ at the time of the carbon ply failure, strength of the carbon ply $\left(S_{\mathrm{C}}\right)$ is substituted into Eq. (3) instead of $\sigma_{\mathrm{C}}$, as is shown in Eq. (4):

$\sigma_{1}=\frac{\sigma_{S R P P(\varepsilon=2 \%)} t_{S R P P}+\mathrm{S}_{C} t_{C}}{t_{S R P P}+t_{C}}$. 


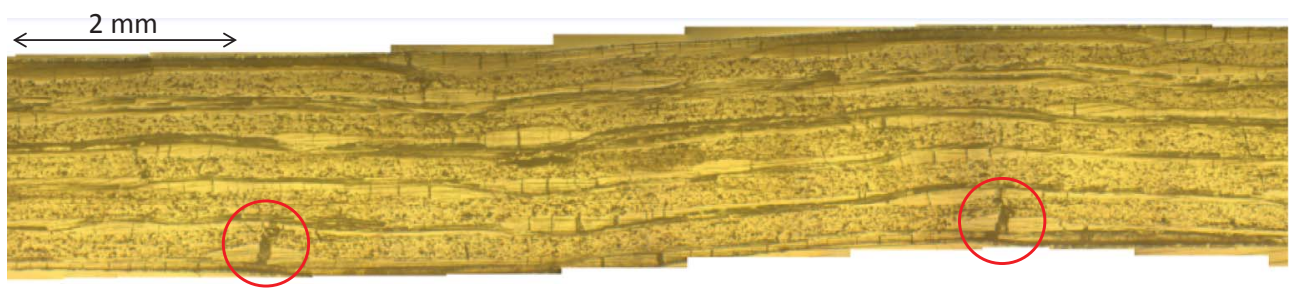

Fig. 7. Microstructure of a broken hybrid with a dispersed layup, PP matrix in the carbon layer and $V_{f}$ of $9.0 \%$. (For interpretation of the references to colour in this figure legend, the reader is referred to the web version of this article.)

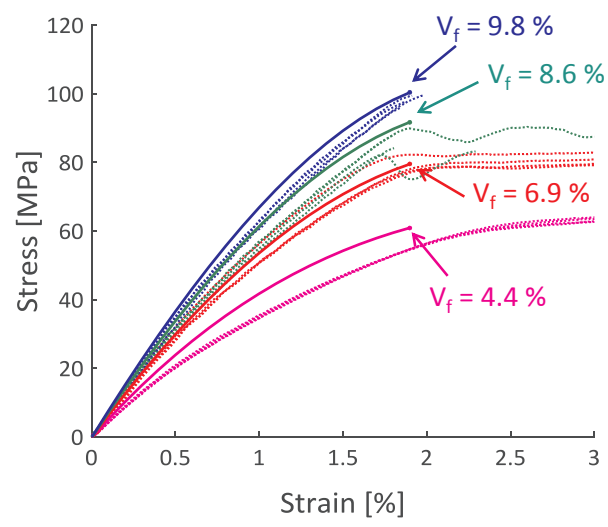

(a)

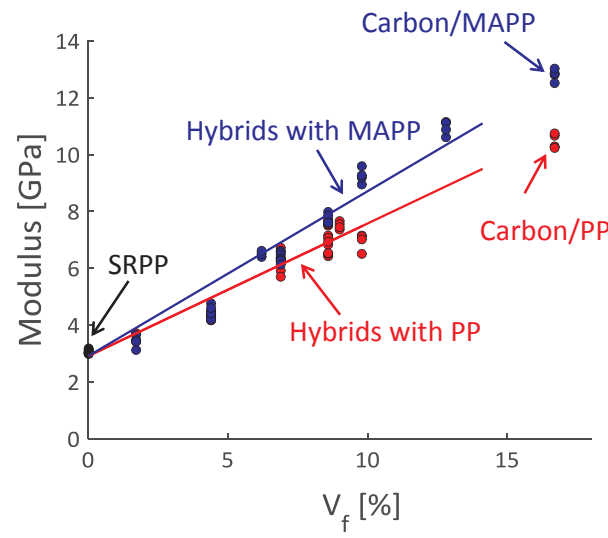

(b)

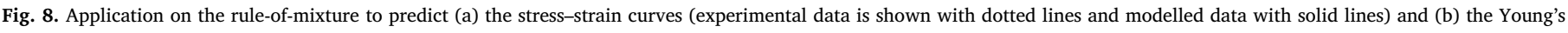
modulus. (For interpretation of the references to colour in this figure legend, the reader is referred to the web version of this article.)

In this equation, $\sigma_{\mathrm{SRPP}(\varepsilon=2 \%)}$ is the stress in SRPP at the failure strain of the carbon ply (about $2 \%$ ). The maximum stress that can be sustained by the hybrid $\left(\sigma_{2}\right)$ following the fracture of the carbon fibre layer is estimated by substituting the strength of SRPP $\left(S_{\mathrm{SRPP}}\right)$ instead of $\sigma_{\mathrm{SRPP}}$ into Eq. (3), as shown in Eq. (5):

$\sigma_{2}=\frac{\mathrm{S}_{S R P P} t_{S R P P}}{t_{S R P P}+t_{C}}$

This equation is based on the simplifying assumption that the contribution of carbon fibre layer is completely eliminated. While (in reality) the carbon fibre ply can still contribute after $\sigma_{1}$ is reached, its contribution (in this equation) is assumed to be zero by the time $\sigma_{2}$ is reached. Stress is assumed to be completely redistributed and stress concentrations are ignored.

In the case of ductile hybrids $\left(\sigma_{2}>\sigma_{1}\right)$, SRPP layers can sustain a higher stress than that at which the carbon fibre ply fracture initially occurred, and the hybrid continues to carry load until the maximum value $\left(\sigma_{2}\right)$.

In the case of the brittle hybrids, the SRPP plies alone cannot sustain a load higher than that at which the carbon fibre ply breaks $\left(\sigma_{2}<\sigma_{1}\right)$. If $\sigma_{2}$ is less than $\sigma_{1}$, there will be an immediate load drop. Depending on the other damage mechanisms, the hybrid may or may not retain some of its load carrying capacity until a higher strain (e.g. MAPP hybrid in Fig. 4b); however, such response can be observed only during a displacement-control test. In a force-control test if $\sigma_{2}$ is less than $\sigma_{1}$, the load drop would constitute an immediate total fracture. This modelling approach between the two limiting stresses does not capture what happens in between $\sigma_{1}$ and $\sigma_{2}$, since it does not consider the stress concentrations, the stress redistribution, the delaminations and the dynamic effect.

The applicability of this criterion, namely comparing $\sigma_{1}$ and $\sigma_{2}$ to predict the truly brittle or ductile failure, is demonstrated in Fig. 9. Hybrids with $\mathrm{V}_{\mathrm{f}}$ of 4.4 and $6.9 \%$ exhibit ductile behaviour $\left(\sigma_{1}<\sigma_{2}\right)$, while that with $9.8 \%$ is clearly brittle $\left(\sigma_{2}<\sigma_{1}\right)$. An interesting behaviour is observed when $\mathrm{V}_{\mathrm{f}}$ is $8.6 \%\left(\sigma_{1} \approx \sigma_{2}\right)$ : some samples experience multiple load drops and the stress rises before the final failure. Each drop corresponds to the development of a crack, which extends over the whole width and thickness of the carbon fibre layer, at a new location (away from the first crack) and is then followed by an increase in the load. This transitional behaviour is observed, because material strengths have a natural variability associated with them. Hence, while $\sigma_{1}$ and $\sigma_{2}$ are about the same based on the average strengths of the carbon fibre and SRPP layers, locally SRPP may or may not be able to sustain the load that is transferred to it once the carbon layer breaks.

Another example of the applicability of this criterion is illustrated by comparing two hybrids with carbon/PP and carbon/MAPP layers, as shown in Fig. 10. In this case, $\sigma_{1}$ is different depending on whether PP or MAPP was used, but $\sigma_{2}$ is the same. The criterion predicts truly ductile behaviour of the hybrid with PP $\left(\sigma_{1}<\sigma_{2}\right)$ and brittle behaviour of the hybrid with MAPP $\left(\sigma_{1}>\sigma_{2}\right)$. Hybrids with MAPP continue to carry $70-80 \%$ of the UTS load in the strain range between 2 and about $8 \%$ strain, as the SRPP tapes gradually debond from the carbon/MAPP layer. Depending on the application, such transitional behaviour might be acceptable since these hybrids offer a higher modulus over the truly ductile ones. These equations provide a useful estimate of the load retention capabilities of the hybrids in the transitional regime.

\subsection{Predicting the transition between brittle and ductile behaviour}

As was shown in the previous section, the simple strength-based criterion that is defined by Eqs. (4) and (5) can be used to assess whether the behaviour of the hybrid will be brittle or ductile. These equations can be applied further to estimate the thickness ratio of the layers or the $\mathrm{V}_{\mathrm{f}}$ that would mark the transition between the two types of behaviour. To find the transitional point, one needs to equate Eq. (4) and (5) and solve for the thickness ratio that would satisfy that relation $\left(\mathrm{t}_{\mathrm{SRPP}} / \mathrm{t}_{\mathrm{C}}\right)$. Layer thicknesses in conjunction with the other properties (e.g. areal weight, density, etc.) can be used to compute the transition $\mathrm{V}_{\mathrm{f}}$.

The UTS and the transition $\mathrm{V}_{\mathrm{f}}$ that were computed, using these formulae for hybrids with PP and MAPP matrices, are represented by the solid lines in Fig. 11, and compared to the experimentally observed strength data. This type of a bi-linear trend is typical for pseudo-ductile 


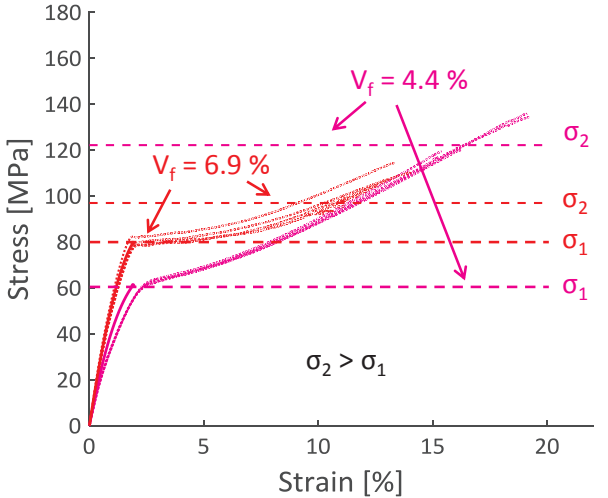

(a)

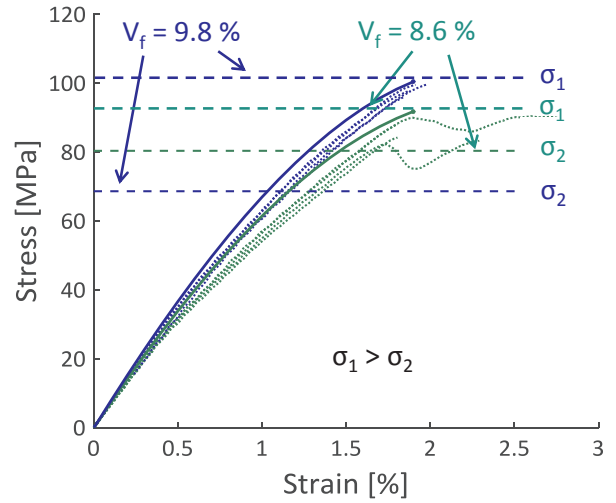

(b)

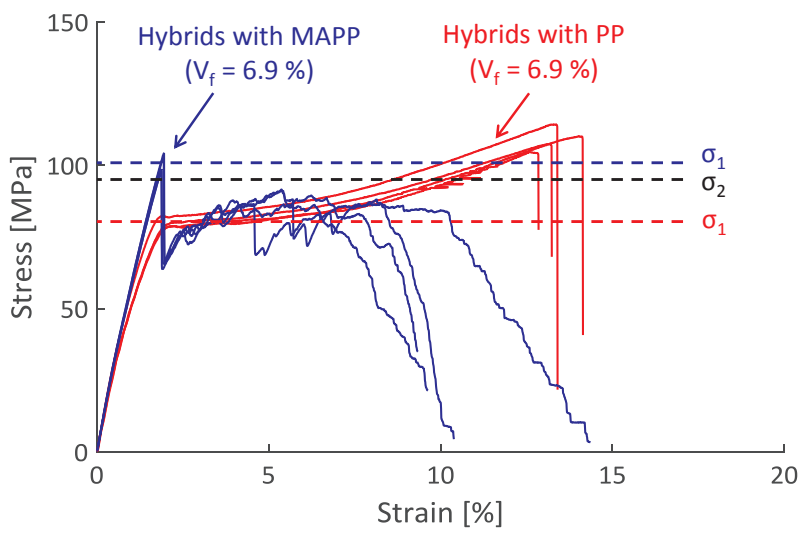

Fig. 10. Application of the strength-criterion to a ductile hybrid with PP and a brittle hybrid with MAPP matrix; both hybrids have the same $\mathrm{V}_{\mathrm{f}}$. (For interpretation of the references to colour in this figure legend, the reader is referred to the web version of this article.)

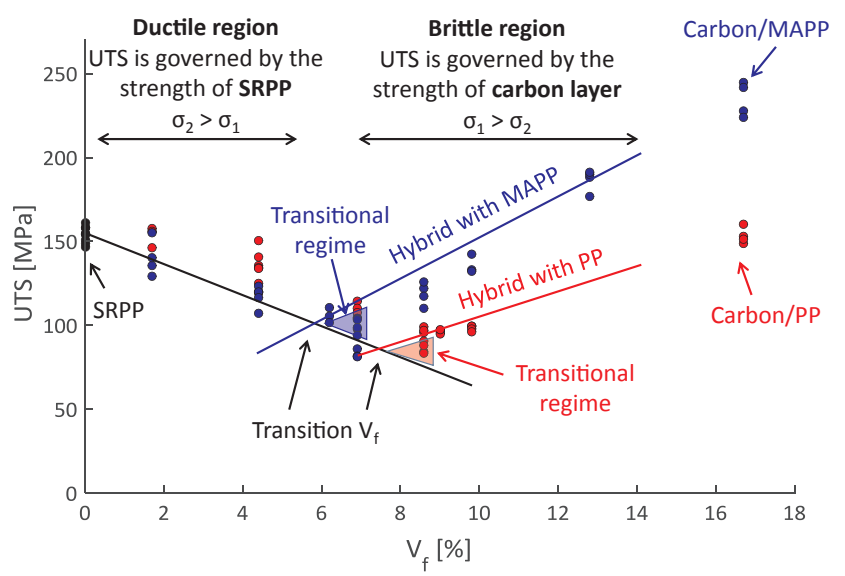

Fig. 11. Bi-linear trend for UTS of hybrids with PP and MAPP. (For interpretation of the references to colour in this figure legend, the reader is referred to the web version of this article.)

hybrids [12]. In the ductile region, the UTS is governed by the strength of SRPP $\left(\sigma_{2}>\sigma_{1}\right)$ and is expected to be the same for hybrids with PP and MAPP. The UTS in the brittle region $\left(\sigma_{2}<\sigma_{1}\right)$ depends on the strength of the carbon fibre layer, and hence, the effect of the matrix adhesion is more pronounced. The transition $\mathrm{V}_{\mathrm{f}}$ for the hybrids with PP and MAPP were calculated to be $7.5 \%$ and $5.8 \%$, respectively. When the difference between $\sigma_{2}$ and $\sigma_{1}$ is relatively small, the hybrid behaviour can be classified as transitional. The presence of the transitional regime is indicated by the triangular zones in Fig. 11, where the upper load level represents UTS and the lower level the load retention after failure of the carbon layer.

\subsection{Concluding remarks about the tensile behaviour}

Tensile tests revealed that modulus and yield stress increase with an increasing $\mathrm{V}_{\mathrm{f}}$. Carbon/MAPP composites are stronger, and their hybrids have higher knee and yield points than their carbon/PP counterparts. The lower properties attained with PP-based composites can be explained by an earlier onset of fibre debonding in the mat.

It was demonstrated that modulus and yield stress can be predicted using the rule of mixtures. The downfall of this method is that it relies on the experimentally measured stress-strain data of the carbon fibre/ PP composite and the SRPP composite plies. In this study, properties of carbon/PP and carbon/MAPP composites with a $\mathrm{V}_{\mathrm{f}}$ of $16.7 \%(/ / 30 / /$ layup) were measured and used for the calculations. To improve the flexibility of this method and extend its usability to hybrids with any internal fibre volume fraction, and different fibre and matrix combinations, an extra tool is needed to model the stress-strain curve of a composite with randomly-oriented discontinuous fibres. One modelling approach that can potentially be applied to this problem is outlined in [28].

The $\mathrm{V}_{\mathrm{f}}$ that marks the transition from brittle to ductile behaviour in hybrids with the nominal layup was experimentally found to be in the range of $6.9-8.6 \%$ for PP-based and $4.4-6.9 \%$ for MAPP-based hybrids. The transition $V_{\mathrm{f}}$ can be calculated using the strength-based failure criterion and results in values of 7.5 and $5.8 \%$ for PP and MAPP hybrids, respectively. The transition occurs at a lower $\mathrm{V}_{\mathrm{f}}$ in MAPP-based hybrids, since it is directly related to the strength of the carbon fibre layer.

It was shown that the transition point can be increased by switching to a dispersed layup, in which the SRPP layers hinder the propagation of transverse cracks from one carbon fibre layer to the others. This effect of the layup could not be captured by the proposed method, because it is designed for hybrids with the nominal layup and assumes that all the carbon fibre layers, being either dispersed or grouped in one thick layer, break at one specific cross-section at one specific strain value. Due to the stochastic nature of crack formation, a crack that develops in one of the carbon layers is shielded of by SRPP and does not imply failure of the whole cross-section, whereas in case the carbon layers are grouped, such shielding does not occur and there is a high probability that the entire thick carbon layer will fail at one cross section. To improve the current model, statistics should be added.

To conclude this section on tensile properties, a comparison is made between carbon fibre mat/SRPP hybrids with $\mathrm{V}_{\mathrm{f}}$ in the range of 1.7-8.6\% and other conventionally used materials, as shown in Fig. 12. This Ashby plot was generated using the ESAComp 5.0 software. This plot illustrates the unique combination of specific modulus (stiffness of $3.5-7 \mathrm{GPa}$, density of $\sim 1000 \mathrm{~kg} / \mathrm{m}^{3}$ ) and ductility (6-18\% strain at 


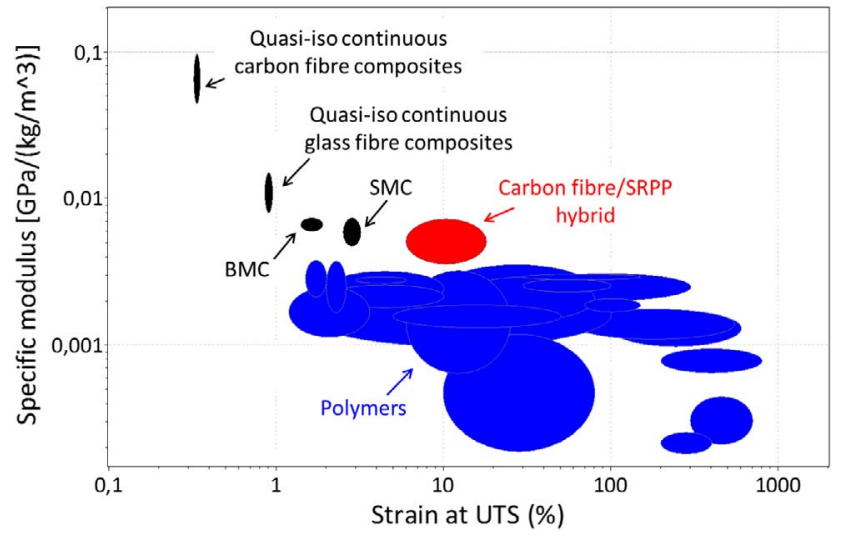

Fig. 12. Ashby plot comparing carbon fibre/SRPP hybrids with other materials in terms of specific modulus and elongation. (For interpretation of the references to colour in this figure legend, the reader is referred to the web version of this article.)

UTS) offered by hybrids and demonstrates their competitive edge over the bulk moulding compounds (BMC) and sheet moulding compounds (SMC).

\section{Results: impact resistance}

\subsection{Impact responses}

All the results presented in this section correspond to composites with PP matrix. Results on MAPP variants will be reported later. The first insights into the impact energy absorption characteristics of the hybrids and the sub-laminates (i.e. carbon/PP and SRPP) can be obtained from the force-displacement response of the penetrating impactor (see Fig. 13). In order to compare the behaviour of carbon/PP and SRPP specimens, the force data was normalised by the specimen thickness. By comparing curves pertaining to these two composites, four main differences can be highlighted (Fig. 13a):

- SRPP has a significantly higher peak stress than carbon/PP (6000 vs. $1200 \mathrm{~N} / \mathrm{mm}$ ). The peak stress is typically related to penetration.

- SRPP has a larger area under the curve than carbon/PP (30 vs. $5 \mathrm{~J} /$ $\mathrm{mm}$ ). This area is indicative of the amount of absorbed energy.

- SRPP has a higher displacement value that corresponds to the peak load than carbon/PP (0.012 vs. $0.002 \mathrm{~mm})$. This implies that SRPP experiences more flexural deformation prior to fracturing.

- SRPP absorbs most of its energy before the peak $(S P \approx 0.19)$; whereas carbon/PP absorbs most of it after the peak (shape parameter $\mathrm{SP} \approx 5.5$ ).

Next, the force-displacement diagrams of the hybrids (Fig. 13b) are examined. The force data in these plots were normalised by the number of SRPP plies to better demonstrate that hybrids can exhibit two distinct types of behaviour. The curves are either triangular with $\mathrm{SP} \approx 0.28$, and resemble those of SRPP, or have a more rounded appearance with $\mathrm{SP} \approx 1.7$. Interestingly, the triangular curves seem to collapse onto a single master curve. The transition between the two types of behaviour occurs around $V_{f}=5.5-6.9 \%$. It can be postulated that, similarly to tensile properties, when $V_{f}$ is less than this transition value, the global behaviour of the hybrids resembles that of SRPP and they experience larger deformations or strains before the final failure.

\subsection{Damage mechanisms}

To understand the governing damage mechanisms in the hybrids, the damage mechanisms that occur in both types of layers must be examined (see Fig. 14a and b). SRPP samples develop large plastic deformations and exhibit whitening (see Fig. 14a), which is associated

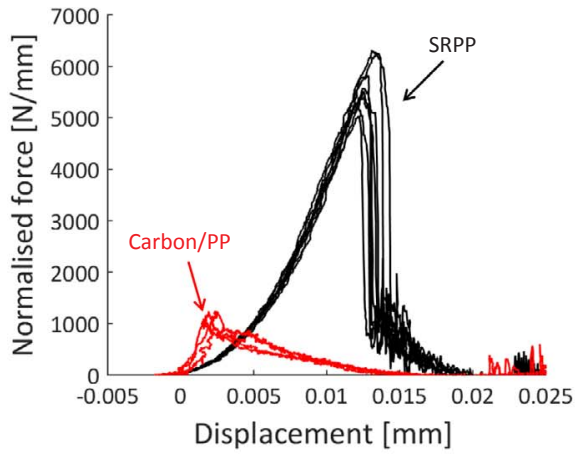

(a)

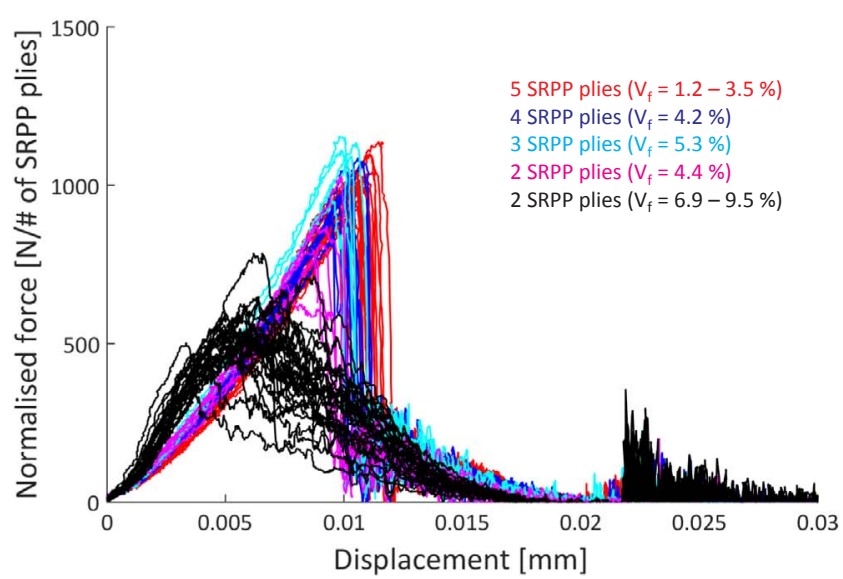

(b)

Fig. 13. Impact force-displacement diagrams of (a) carbon/PP vs. SRPP and (b) their hybrids. In (a) force is normalised by the specimen thickness and in (b) force is normalised by the number of SRPP plies. (For interpretation of the references to colour in this figure legend, the reader is referred to the web version of this article.)

with damage accumulation in SRPP. The overall fracture region has a circular form. It was previously shown [29] that the main energy absorbing mechanisms of SRPP are PP tape debonding, fibrillation and fracture, while the role of delaminations is not that prominent [29]. The latter conclusion was reached, because a linear relationship was obtained between the penetration impact energy and the thickness of SRPP specimens, even for samples with only one single SRPP ply [29]. Damage in carbon/PP specimens seems to be localised to the impacted region, as shown in Fig. 14b. The fracture region has a cross-shaped pattern and shows extensive fibre pull-out, analogous to the tensile carbon fibre-PP specimens (see Fig. 3b, lower picture).

Hybrids exhibit two types of responses during penetration impact, as was shown in the force-displacement curves in Fig. 13b. Better understanding of these responses can be obtained from the post-impact appearance of the specimens (Fig. 14c and d). Examination of hybrids with low carbon fibre volume fraction $\left(\mathrm{V}_{\mathrm{f}}<5.5 \%\right)$ reveals that the entire portion of the specimen that was within the clamps showed some degree of whitening (see Fig. 14c), which is indicative of large permanent deformations and widespread damage accumulation in SRPP. On the contrary, in hybrids with high carbon fibre volume fraction $\left(V_{f}>6.9 \%\right)$, whitening of SRPP was limited to the region where the impactor was in contact with the specimen (Fig. 14d). Such damage localization was also observed in carbon/PP specimens (Fig. 14b). Damage mechanisms that were common to all the samples include fibrillation and debonding of the PP tapes, and debonding and pull-out of the carbon fibres in the mat.

Another difference between the hybrids with high and low carbon fibre $V_{f}$ was in their fracture location. Specimens with low $V_{f}$ show a 


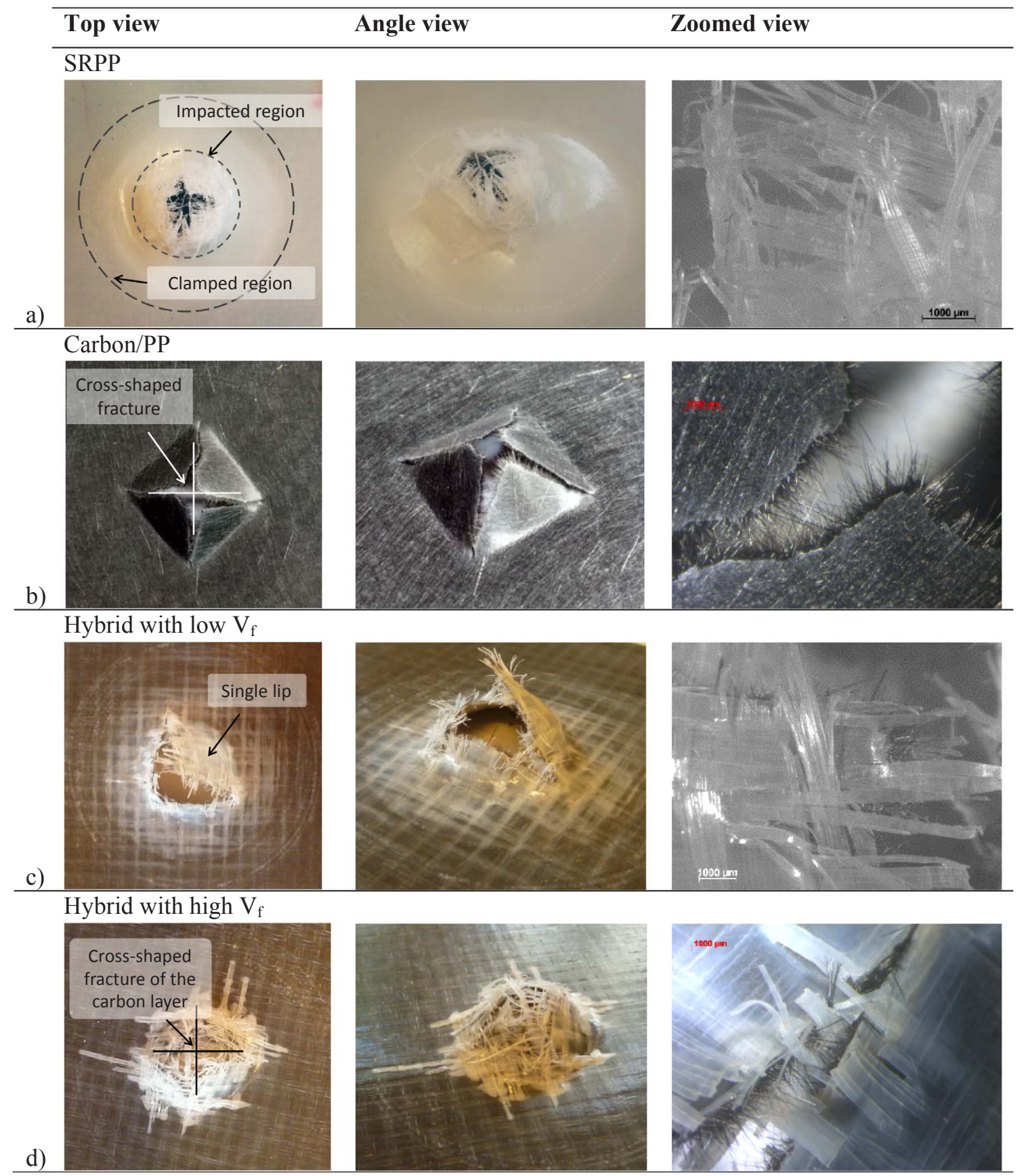

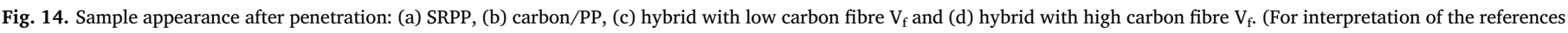
to colour in this figure legend, the reader is referred to the web version of this article.)

single large lip with fracture happening close to the perimeter of the impacted region (Fig. 14c). Hybrids with high $\mathrm{V}_{\mathrm{f}}$ develop cross-shaped fracture of carbon layer with four lips (Fig. 14d), similar to that observed in carbon/PP samples (Fig. 14b).

Overall, based on the examination of the penetrated specimens it can be concluded that hybrids with low carbon fibre fraction behave like SRPP samples and experience large out-of-plane deformations before penetration. On the other hand, deformation and damage of hybrids with high carbon fibre fraction are localised, which is also true for carbon/PP samples. It can be hypothesised that due to the increased stiffness and brittleness, such hybrids do not deform significantly before penetration.

\subsection{Scalability of impact data}

To continue the discussion of the main trends, a more quantitative analysis of the data is considered in this section. The penetration impact energy test data are summarised in Fig. 15. In Fig. 15a the data are normalised with respect to the panel thickness, which is the conventional approach used to report and compare impact performance of the materials. It can be highlighted that hybrids with low $\mathrm{V}_{\mathrm{f}}(<5.5 \%)$ demonstrate good impact performance with energy absorbing abilities over $20 \mathrm{~J} / \mathrm{mm}$, hence retaining about $70 \%$ of the SRPP performance. Even hybrids with higher $\mathrm{V}_{\mathrm{f}}$ can absorb at least 3 times more energy than pure carbon/PP composites.

In Fig. 15b the impact energy data are normalised by the number of SRPP plies, which all have equal individual thickness. This normalisation was applied to demonstrate the scalability of the penetration 


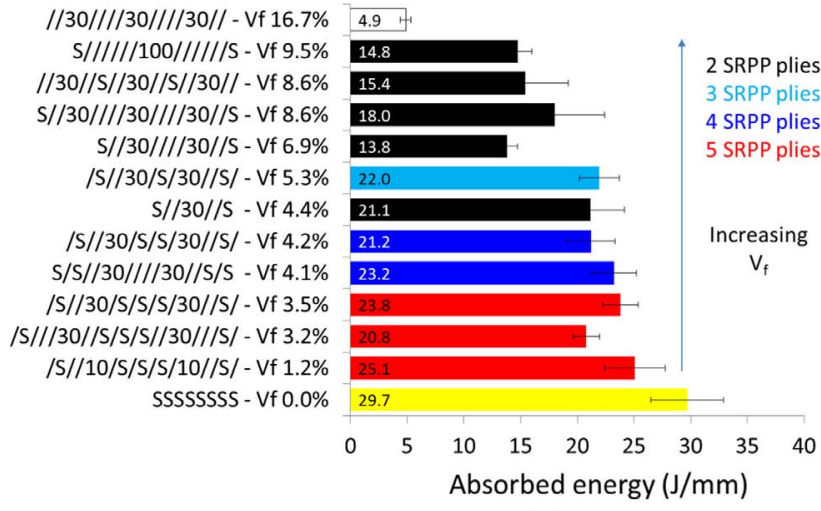

(a)

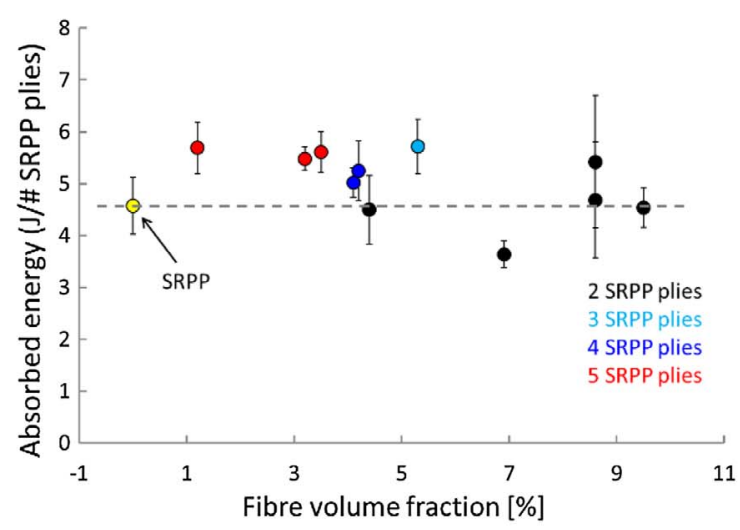

(b)

Fig. 15. Total impact energy absorbed by SRPP and hybrids normalised (a) by the thickness of the panel and (b) by the number of SRPP plies. The data is colour coordinated depending on the number of SRPP plies a hybrid has. (For interpretation of the references to colour in this figure legend, the reader is referred to the web version of this article.)

impact data and to show that the total amount of energy absorbed (up to penetration) by a (ductile) hybrid can be estimated by accounting for just the number of SRPP plies. This is not surprising since SRPP absorbs significantly more energy than carbon/PP does (30 vs. $5 \mathrm{~J} / \mathrm{mm}$ ). Such scaling provides a lower bound estimate for the total amount of energy that a hybrid can absorb, which is useful from the application point of view. The rule of mixture can in principle be employed as well by accounting for the contribution of the carbon fibre plies and is expected to provide a more accurate estimate. It was not used in this paper, because only carbon/PP specimens with $\mathrm{V}_{\mathrm{f}}$ of $16.7 \%$ were tested whereas hybrids had various internal fibre volume fractions (e.g. //30/ vs. ///30// building blocks). Thus, a more conservative approach of scaling based on the number of SRPP plies was adopted.

\subsection{Concluding remarks about the impact behaviour}

Based on the comparison of the force-displacement diagrams (Fig. 13) and the post-mortem examination of the specimens (Fig. 14), it was found the hybrids exhibit two distinct types of behaviour. At lower $\mathrm{V}_{\mathrm{f}}(<5.5 \%)$, their response resembles that of SRPP, such that there is widespread damage in the specimen and the force-displacement curve is characterized by a low shape parameter. At higher $\mathrm{V}_{\mathrm{f}}$ ( $>6.9 \%$ ), the influence of the carbon/PP layer(s) becomes more prominent, such that damage becomes more localised and the shape parameter is high. Similarly to the tensile behaviour, there is also a transition point in the impact response of hybrids.

It was concluded that in hybrids with low $\mathrm{V}_{\mathrm{f}}$, the energy absorption is dominated by deformation and damage development in the SRPP layers. The presence of carbon/PP in low amounts does not seem to alter the energy absorption capabilities of the SRPP plies. The main mechanisms remain PP tape fibrillation, fracture and debonding. Similarly, in tensile samples the SRPP layers tend to debond internally rather than to delaminate from the carbon fibre layer [30]. Furthermore, as shown in Fig. 13b, the force-displacement curves of low $V_{f}$ hybrids collapse onto a single master curve that resembles the behaviour of SRPP (Fig. 13a) when normalised by the number of SRPP plies.

These observations provide the basis for the proposed method to estimate the amount of energy that carbon fibre/ SRPP hybrids with a $\mathrm{V}_{\mathrm{f}}<9.5 \%$ can absorb. Their energy absorption capabilities can be estimated solely from the number of SRPP plies that it contains. As was shown in Fig. 15, the amount of energy absorbed by SRPP alone does provide a conservative estimate needed for preliminary design, without having to develop a complex finite element model. A more accurate estimate can be achieved by considering the presence of the carbon fibre layers if their impact properties are known. It is noteworthy, that the validity of this estimate at $\mathrm{V}_{\mathrm{f}}$ beyond the transition $(>6.9 \%)$ is arguable, since the shapes of the force-displacement curves and damage mechanism differ from those of pure SRPP, and must the used with caution.

\section{Conclusions}

The development and the potential of novel pseudo-ductile hybrids that consist of carbon fibre mat reinforced PP and self-reinforced PP (SRPP) were discussed. A clear transition between brittle and ductile behaviour was observed in tensile and impact performance. Brittle hybrids developed localised damage, while ductile ones had more dispersed damage. The shapes of the tensile stress-strain curves and impact force-displacement curves of ductile hybrids resemble those of SRPP. Tensile and impact curves of brittle hybrids have a more distinct appearance.

The stacking sequence was found to have a strong effect on the tensile properties. In a dispersed layup stochastic effects play an important role in delaying specimen breakage, since fracture of a single carbon layer at one location does not constitute immediate failure of all the carbon layers at that location, because it is impeded by the presence of tough SRPP plies. Thus, dispersed hybrids have a higher transition $V_{f}$ than their nominal counterparts. Interestingly, the influence of the layup on impact performance was not as profound. This observation can be explained by two reasons. Even though the layup can affect the way carbon layers fracture during an impact test, their energy absorption capacity is much lower than that of SRPP plies, and hence any change in impact failure mechanisms in the carbon fibre plies would have a minimal effect on the total absorbed energy.

The fibre/matrix adhesion was found to have a strong effect on tensile properties and damage mechanisms in carbon fibre composites and carbon fibre/SRPP hybrids alike. In comparison to specimens with high adhesion MAPP, those with regular PP (resulting in a lower adhesion between carbon fibres and the PP matrix) have a lower stiffness and yield stress. This is related to the earlier onset of fibre debonding even at very low strains due to a weak fibre/matrix interface. On the other hand, the transition $\mathrm{V}_{\mathrm{f}}$ is higher in hybrids with a PP matrix. As was shown analytically, the difference in the transition $V_{f}$ can be attributed to the relative difference in strength between the carbon/PP and carbon/MAPP composites.

It was demonstrated that simple analytical models can be used to estimate the tensile modulus, UTS and impact energy absorption of carbon fibre/SRPP hybrids. Future work on modelling will encompass the implementation of an effective fracture-toughness based criterion to capture the gradual debonding of the SRPP tapes and implementation of progressive damage development in the carbon fibre layer to capture the stress-strain curve after yielding and to estimate the failure strain.

Overall, the pseudo-ductile hybrids that were developed demonstrated a unique combination of mechanical properties. The use of discontinuous fibres has reduced the large load drop that was observed 
in previous publications on hybrids with SRPP and continuous carbon fibres [8-10]. The (dispersed) hybrid with $8.6 \%$ carbon fibres combines a high stiffness of $7 \mathrm{GPa}$ with a high ductility (expressed by its failure strain) of $>6 \%$, while a threefold increase in the yield stress in comparison to the SRPP was achieved and the penetration impact energy was kept at a high level $(>15 \mathrm{~J} / \mathrm{mm})$. Hence, hybrid carbon fibre SRPP composites offer a competitive advantage over bulk and sheet moulding compounds.

\section{Acknowledgments}

The authors would also like to acknowledge the funding and the materials provided by Toray Industries, Inc. as well as all the fruitful discussions that have led to the initiation of this project and its swift progress. The authors acknowledge the initial work of Dr. Joris Baets, which was the trigger for this more detailed study. Yentl Swolfs also extends his gratitude to the FWO Flanders for his postdoctoral fellowship. Ignaas Verpoest is emeritus holder of the Toray Chair at KU Leuven.

\section{References}

[1] Swolfs Y, et al. The influence of weave architecture on the mechanical properties of self-reinforced polypropylene. Compos A Appl Sci Manuf 2013;53:129-36.

[2] Swolfs $Y$, et al. Failure behaviour of self-reinforced polypropylene at and below room temperature. Compos A Appl Sci Manuf 2014;65:100-7.

[3] Schneider C, et al. Compression and tensile properties of self-reinforced poly (ethylene terephthalate)-composites. Polym Test 2012. (0).

[4] Hine PJ, et al. The hot compaction behaviour of woven oriented polypropylene fibres and tapes. I. Mechanical properties. Polymer 2003;44(4):1117-31.

[5] Czél G, Jalalvand M, Wisnom MR. Design and characterisation of advanced pseudoductile unidirectional thin-ply carbon/epoxy-glass/epoxy hybrid composites. Compos Struct 2016;143:362-70.

[6] Czél G, Jalalvand M, Wisnom MR. Demonstration of pseudo-ductility in unidirec tional hybrid composites made of discontinuous carbon/epoxy and continuous glass/epoxy plies. Compos A Appl Sci Manuf 2015;72:75-84.

[7] Czél G, Wisnom MR. Demonstration of pseudo-ductility in high performance glass/ epoxy composites by hybridisation with thin-ply carbon prepreg. Compos A Appl Sci Manuf 2013;52:23-30.

[8] Swolfs Y, et al. Tensile behaviour of intralayer hybrid composites of carbon fibre and self-reinforced polypropylene. Compos A Appl Sci Manuf 2014:59:78-84.

[9] Swolfs Y, et al. Introducing ductility in hybrid carbon fibre/self-reinforced composites through control of the damage mechanisms. Compos Struct 2015;131:259-65.

[10] Swolfs Y, et al. The importance of bonding in intralayer carbon fibre/self-reinforced polypropylene hybrid composites. Compos A Appl Sci Manuf 2015;76:299-308.

[11] Bunsell AR, Harris B. Hybrid carbon and glass fibre composites. Composites 1974;5(4):157-64.

[12] Manders PW, Bader MG. The strength of hybrid glass/carbon fibre composites. Part 1. Failure strain enhancement and failure mode. J Mater Sci 1981;16(8):2233-45

[13] Jones KD, Dibenedetto AT. Fiber fracture in hybrid composite systems. Compos Sci Technol 1994;51(1):53-62.

[14] Somboonsong W, Ko FK, Harris HG. Ductile hybrid fiber reinforced plastic reinforcing bar for concrete structures: design methodology. ACI Mater J 1998;95(6):655-66.

[15] Swolfs Y, Gorbatikh L, Verpoest I. Fibre hybridisation in polymer composites: a review. Compos A Appl Sci Manuf 2014;67:181-200.

[16] Jalalvand M, Czél G, Wisnom MR. Damage analysis of pseudo-ductile thin-ply UD hybrid composites - a new analytical method. Compos A: Appl Sc Manuf 2015;69:83-93.

[17] Jalalvand M, Czél G, Wisnom MR. Parametric study of failure mechanisms and optimal configurations of pseudo-ductile thin-ply UD hybrid composites. Compos A Appl Sci Manuf 2015;74:123-31.

[18] Wisnom MR, et al. Hybrid effects in thin ply carbon/glass unidirectional laminates: accurate experimental determination and prediction. Compos A Appl Sci Manuf 2016;88:131-9.

[19] Enfedaque A, et al. Effect of glass fiber hybridization on the behavior under impact of woven carbon fiber/epoxy laminates. J Compos Mater 2010;44(25):3051-68.

[20] Kowsika MV, Mantena PR. Static and low-velocity impact response characteristics of pultruded hybrid glass-graphite/epoxy composite beams. J Thermoplast Compos Mater 1999;12(2):121-32.

[21] Sevkat E, et al. Drop-weight impact of plain-woven hybrid glass-graphite/toughened epoxy composites. Compos A Appl Sci Manuf 2009;40(8):1090-110.

[22] Swolfs $Y$, et al. The influence of process parameters on the properties of hot compacted self-reinforced polypropylene composites. Compos A Appl Sci Manuf 2014;65:38-46.

[23] Hirano N, Muramatsu H, Inoue T. Study of fibre length and fiber-matrix adhesion in carbon-fiber-reinforced polyprolylenes. Adv Compos Mater 2014;23(2):151-61.

[24] Toray Carbon Fibres America, I., Torayca (R) T700S data sheet.

[25] Pegoretti A, et al. Intraply and interply hybrid composites based on E-glass and poly (vinyl alcohol) woven fabrics: tensile and impact properties. Polym Int 2004;53(9):1290-7.

[26] Beaumont PWR, Riewald PG, Zweben C. Methods for improving the impact resistance of composite materials. In: Foreign Object Impact Damage to Composites, ASTM STP 568. 1974, American Society for Testing and Materials. p. 134-58.

[27] Tsai SW, Melo JDD. Composite materials design and testing: unlocking mystery with invariants. 2015: composites design group. Department of Aeronautics \& Astronautics, Stanford University; 2015.

[28] Jain A. Hybrid multi-scale modelling of damage and fatigue in short fiber reinforced composites (Ph.D thesis). KU Leuven: Leuven, Belgium: Department of Materials Engineering; 2015. p. 301.

[29] Meerten Y, et al. Penetration impact testing of self-reinforced composites. Compos A Appl Sci Manuf 2014;68:289-95.

[30] Selezneva M, et al. Analysis of failure mechanisms in hybrid carbon fibre/self-reinforced polypropylene composites. In: ECCM17 - 17th European Conference on Composite Materials; 2016. Munich, Germany. 